\title{
Glutathione prevents ethanol induced gastric mucosal damage and depletion of sulfhydryl compounds in humans
}

\author{
C Loguercio, D Taranto, F Beneduce, C del Vecchio Blanco, A de Vincentiis, \\ G Nardi, M Romano
}

\begin{abstract}
Whether parenteral administration of reduced glutathione prevented ethanol induced damage to and depletion of sulfhydryl compounds in the human gastric mucosa was investigated. Ten healthy volunteers underwent endoscopy on three separate occasions. Gastric mucosal damage was induced by spraying $80 \%$ ethanol on to the gastric mucosa through the biopsy channel of the endoscope. The gastric mucosal score, total sulfhydryls, glutathione, and cysteine were evaluated in basal conditions and after ethanol administration with and without pretreatment with parenteral glutathione. Glutathione significantly decreased the extent of ethanol induced macroscopic injury to the mucosa of the gastric body and antrum. Glutathione's protective effect is associated with appreciable inhibition of ethanol induced depletion of gastric sulfhydryl compounds. This is the first report of protection against ethanol induced gastric mucosal damage by a sulfhydryl containing agent in humans.

(Gut 1993; 34: 161-165)
\end{abstract}

Ethanol induced gastric mucosal damage is associated with a significant reduction in the nonprotein sulfhydryl concentration in the rat and dog. ${ }^{12}$ We have recently shown that in humans too the gastric mucosal damage induced by $80 \%$ ethanol is associated with a depletion of total sulfhydryls (that is, protein and non-protein) as well as of reduced glutathione and cysteine in both the gastric body and antrum. ${ }^{3}$

Sulfhydryl containing agents have been reported to protect the gastric mucosa from ethanol induced damage in experimental animals. $^{1+5}$ Whether sulfhydryl compounds exhibit similar gastric mucosal protective property in humans has not been evaluated.

We hypothesised that maintenance of gastric endogenous sulfhydryl compounds might be important for the gastric mucosa to resist challenge with ethanol. Therefore this study was aimed to assess whether parenteral administration of glutathione prevented ethanol induced depletion of gastric sulfhydryl compounds and gastric mucosal damage in humans.

\section{Methods}

Research was carried out according to the principles of the Declaration of Helsinki. The study was approved by the institutional human experimentation committee.
We studied 10 healthy men (age range 28-50 years, median 40 years), whose gastric mucosa was found to be normal by endoscopy and histology. There was no previous history of gastrointestinal disease or alcohol abuse nor were the subjects taking any drug. Haemorrhagic diathesis was excluded. Informed consent was obtained.

Each subject underwent three endoscopies on three separate occasions 7-10 days apart. At the first endoscopy, after evaluation of the gastric mucosal score according to Agrawal, et al ${ }^{6}$ (Table I), six to eight biopsy specimens were taken from the gastric body and antrum for histological evaluation and baseline determination of sulfhydryl, glutathione, and cysteine. At the second and third endoscopy, each subject was given intravenously and in random order normal saline $(100 \mathrm{ml} / 10$ minute $)$ or reduced glutathione (Tationil-Boehringer Mannheim-Italia) $2.4 \mathrm{~g}$ in $100 \mathrm{ml}$ of normal saline $/ 10$ minute. At the end of the infusion, $40 \mathrm{ml}$ of $80 \%$ ethanol were sprayed along the greater curvature of the stomach from the antrum up to the mid-gastric body, via a catheter passed through the biopsy channel of the endoscope. The endoscope was withdrawn and 30 minutes were allowed to lapse before a new endoscopy was performed to assess gastric mucosal score and to take six to eight biopsy specimens from the gastric body and antrum for sulfhydryl determination. Specimens were taken from the areas that had been exposed to ethanol but haemorrhagic or erosive lesions were avoided. The gastric mucosa was observed immediately before biopsy and a blinded endoscopist (DT) graded the mucosal findings.

We also studied glutathione and cysteine plasma concentrations after an infusion of glutathione $(2 \cdot 4 \mathrm{~g} / 10$ minutes $)$ in five subjects.

\section{HANDLING OF BIOPSY SPECIMENS}

Two specimens were fixed in $10 \%$ formalin and stained with haematoxilin and eosin for standard histology. The remaining tissue samples from each subject were combined, gently washed with ice cold saline, weighed, and immediately stored at $-80^{\circ} \mathrm{C}$ until assay. Before assay, the tissue samples were allowed to thaw briefly and were then homogenised in $0.02 \mathrm{M}$ EDTA at $4^{\circ} \mathrm{C}$ (final volume $500 \mu \mathrm{l}$ ) in a Potter-Elvehjem homogenising tube. The total sulfhydryl content was determined colorimetrically. ${ }^{7}$ Glutathione and cysteine were measured by the method of Newton, et al, ${ }^{8}$ as described previously. ${ }^{9}$ Briefly, tissue samples were homogenised in $0.02 \mathrm{M}$ EDTA at $4^{\circ} \mathrm{C}$ with $10 \mu \mathrm{l}$ of $50 \mathrm{mM}$ monobromo- 
TABLE I Gastroscopy rating scale

\begin{tabular}{ll}
\hline Grade & Description \\
\hline 0 & Normal mucosa \\
1 & Hyperaemia \\
2 & Single submucosal haemorrhagic lesion \\
3 & $2-5$ submucosal haemorrhagic lesions \\
4 & $5-10$ submucosal haemorrhagic lesions \\
5 & $>10$ submucosal haemorrhagic lesions or \\
6 & a large, confluent haemorrhagic area \\
\hline
\end{tabular}

TABLE II Effect of $80 \%$ ethanol on gastric mucosal score in normal saline and glutathione pretreated subjects. (Values, mean (SEM), $n=10$ per study group.)

\begin{tabular}{|c|c|c|}
\hline \multirow[b]{2}{*}{ Treatment } & \multicolumn{2}{|c|}{ Gastric mucosal score } \\
\hline & Body & Antrum \\
\hline $\begin{array}{l}\text { None (control) } \\
\text { Normal saline, ethanol } \\
\text { Glutathione, ethanol }\end{array}$ & $\begin{array}{l}0 \cdot 0(0 \cdot 0) \\
2 \cdot 8(0 \cdot 4) \dagger \\
1 \cdot 2(0 \cdot 2)^{\star} \ddagger\end{array}$ & $\begin{array}{l}0 \cdot 0(0 \cdot 0) \\
1 \cdot 5(0 \cdot 2) \dagger \\
0 \cdot 3(0 \cdot 2)^{\star}, \mathrm{NS}\end{array}$ \\
\hline
\end{tabular}

TABLE III Effect of $80 \%$ ethanol on gastric total sulfhydryls in normal saline and glutathione pretreated subjects. Values, median (ranges), $n=10$ per study group.

\begin{tabular}{lll}
\hline & \multicolumn{2}{l}{$\begin{array}{l}\text { Gastric total sulfhydryls } \\
\text { (nmollg wet tissue) }\end{array}$} \\
\cline { 2 - 3 } Treatment & Body & Antrum \\
\hline None (control) & 3050 & 2350 \\
Normal saline, ethanol & $(2770-3620)$ & $(1900-3300)$ \\
Glutathione, ethanol & $1550 \ddagger$ & $925 \ddagger$ \\
& $(1000-2400)$ & $(660-1900)$ \\
& $2200^{\star} \dagger$ & $1800^{\star} \dagger$ \\
& $(1300-3000)$ & $1100-2300)$ \\
\hline
\end{tabular}

${ }^{\star} \mathrm{p}<0.05 v$ normal saline, ethanol; $\nmid \mathrm{p}<0.01 v$ control; $\ddagger \mathrm{p}<0.001 v$ control.

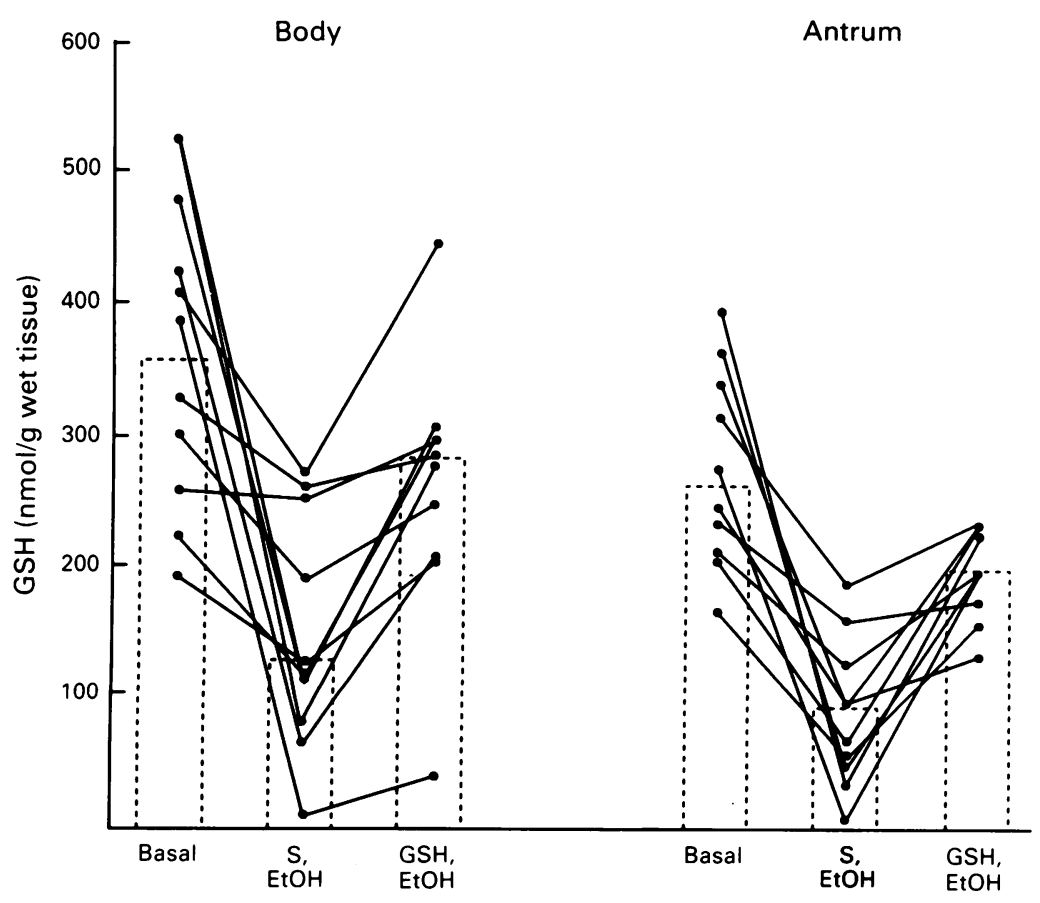

Figure 1: Effect of parenteral glutathione (GSH) on gastric GSH tissue concentrations in the gastric body and antrum. (Individual values and median (bars) given; $n=10$ per study group.) Basal $v$ normal saline (S), ethanol $(\mathrm{EtOH})$ : body $\mathrm{p}<0.001$, antrum $\mathrm{p}<0.001$.

Basal $v$ glutathione (GSH), EtOH: body $\mathrm{p}: \mathrm{NS}$, antrum $\mathrm{p}<0 \cdot 01$.

$\mathrm{S}, \mathrm{EtOH} v \mathrm{GSH}, \mathrm{EtOH}$ : body $\mathrm{p}<0.05$, antrum $\mathrm{p}<0.001$. bimane (Thiolyte MBBR-Calbiochem) in acetonitrile and $20 \mu \mathrm{l}$ of $\mathrm{N}$-ethyl-morpholine $\mathrm{pH} 8$ for derivatisation of sulfhydryl groups. After 15 minutes reaction in the dark, proteins were precipitated by $10 \%$ sulphosalicylic acid and removed by centrifugation at $13800 \mathrm{~g}$ for 5 minutes. The supernatant was filtered (Millipore $0.45 \mu \mathrm{m})$ and injected into a HPLC column (Beckman Mod 330 fitted with a Waters U6K injector and provided with a Shimadzu RF 530 fluorescence detector). The column was an Altex Ultrasphere ODS $\mathrm{C} 18$. The analyses were run at a flow rate of $1 \mathrm{ml} / \mathrm{minute}$, with $18 \%$ methanolwater containing $2 \cdot 5 \%$ acetic acid. Ten to 100 nmol of glutathione and cysteine were treated as the samples to provide derivatised standards. Reduced sulfhydryls were expressed as $\mathrm{nmol} / \mathrm{g}$ of wet tissue.

\section{DETERMINATION OF PLASMA GLUTATHIONE AND} CYSTEINE

In five subjects, the plasma concentrations of glutathione and cysteine were measured before and after infusion of glutathione $2.4 \mathrm{~g} /$ $100 \mathrm{ml}$ normal saline $/ 10$ minutes. Blood samples were taken before glutathione infusion (time point 0 ), immediately after the end of glutathione infusion, and then at 5 minute intervals over a 70 minute period. Samples were treated as described previously. ${ }^{10}$ Glutathione and cysteine concentrations were measured as described above and were expressed as $\mu \mathrm{mol} / \mathrm{l}$.

\section{STATISTICAL ANALYSIS}

Data are expressed as mean (SEM) or as median and ranges when data were not distributed normally. The significance of differences was assessed by ANOVA followed by Duncan's multiple range test ${ }^{11}$ or by Wilcoxon rank sum test, as appropriate. Correlation was evaluated by regression analysis. Differences were considered to be significant if $\mathrm{p}<0 \cdot 05$.

\section{Results}

Parenteral administration of glutathione significantly decreased ethanol induced damage to the gastric body and antrum (Table II). In fact, pretreatment with glutathione reduced the gastric mucosal score from $2 \cdot 8(0 \cdot 4)$ to $1 \cdot 2(0 \cdot 2)$ $(\mathrm{p}<0.01 v$ normal saline pretreated subjects $)$ in the gastric body and from $1.5(0.2)$ to $0.3(0.2)$ $(\mathrm{p}<0.01 v$ normal saline pretreated subjects $)$ in the antrum.

Pretreatment with glutathione significantly prevented the total sulfhydryl depletion brought about by ethanol (Table III). In fact, total sulfhydryl tissue concentrations in normal saline or glutathione-pretreated subjects were decreased by $49 \%$ and $28 \%$, respectively, in the gastric body (normal saline, ethanol $v$ glutathione, ethanol: $\mathrm{p}<0.05$ ), and by $61 \%$ and $23 \%$, respectively, in the antrum (normal saline, ethanol $v$ glutathione, ethanol: $\mathrm{p}<0.05)$.

Figure 1 shows the effect of parenteral administration of glutathione on the ethanol induced fall in glutathione concentrations in the gastric body and antrum. Ethanol caused the 


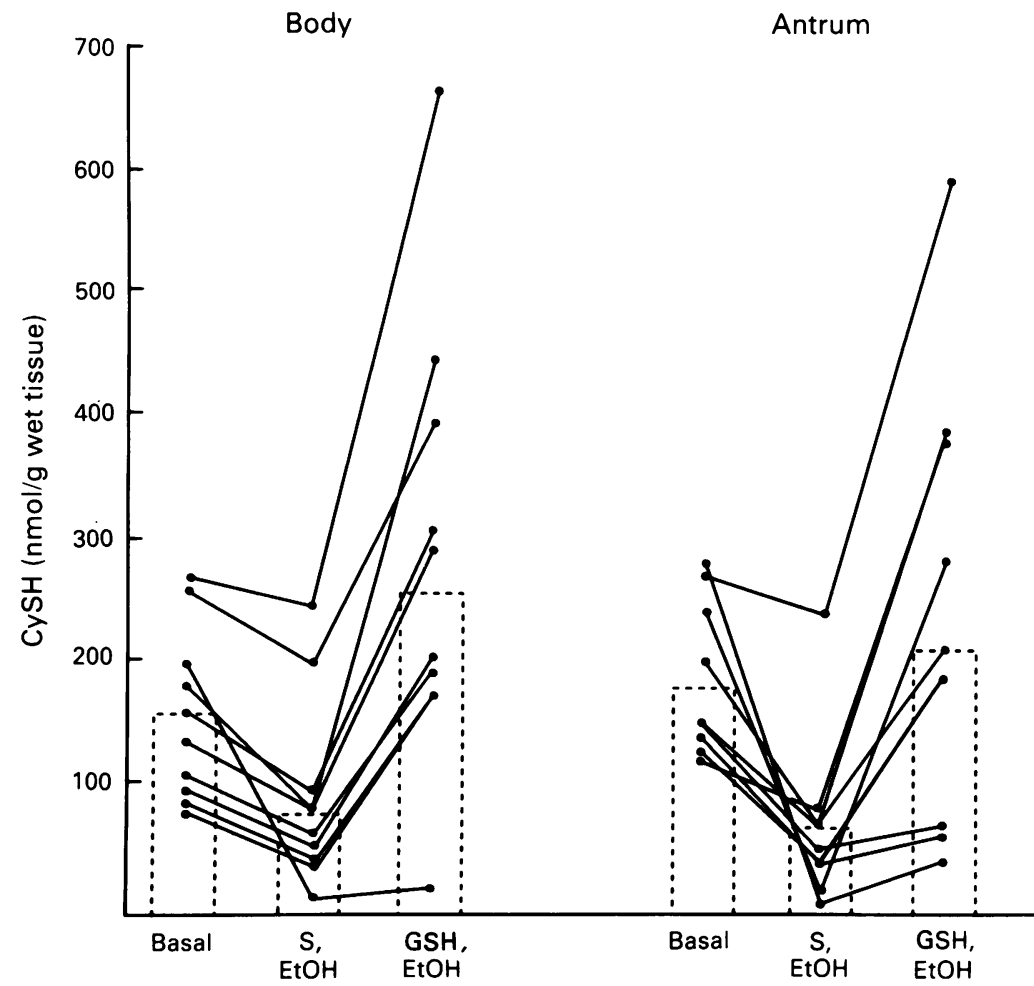

Figure 2: Effect of parenteral glutathione $(G S H)$ on cysteine $(C y S H)$ gastric tissue concentrations in normal saline $(S)$ and $G S H$ pretreated subjects. (Individual values and median (bars) given; $n=10$ per study group.)

Basal $v \mathrm{~S}$, ethanol $(\mathrm{EtOH})$ : body $\mathrm{p}<0 \cdot 05$, antrum $\mathrm{p}<0 \cdot 001$.

Basal $v$ GSH, EtOH: body $\mathrm{p}<0 \cdot 05$, antrum $\mathrm{p}$ : NS.

$\mathrm{S}, \mathrm{EtOH} v \mathrm{GSH}, \mathrm{EtOH}$ : body $\mathrm{p}<0.01$, antrum $\mathrm{p}<0.01$.

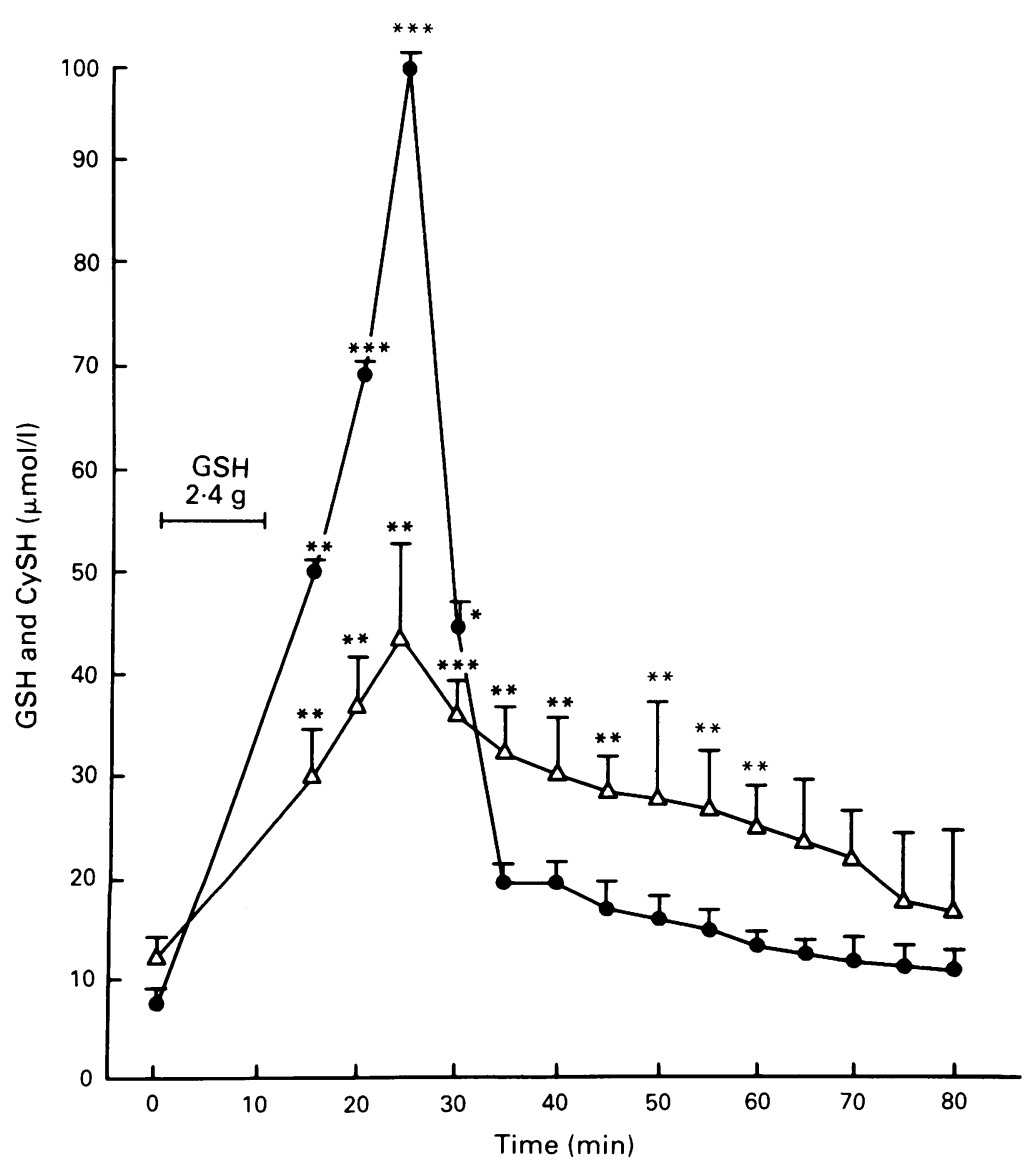

Figure 3: Glutathione $(G S H)(-\bigcirc)$ and cysteine $(C y S H)(\triangle-\triangle)$ plasma concentrations after GSH infusion. (Values, mean $S E M), n=5:{ }^{\star} p<0 \cdot 05 ;{ }^{\star \star} p<0 \cdot 01$ $\star \star \star p<0 \cdot 001$.) tissue glutathione concentration to drop by $65 \%$ $(\mathrm{p}<0.001 v$ baseline value) in the gastric body and by $66 \%(\mathrm{p}<0.001 v$ baseline value $)$ in the antrum. In glutathione-pretreated subjects, however, the ethanol-induced decrease in tissue glutathione was only $21 \%$ in the gastric body $(\mathrm{p}<0.05 v$ normal saline pretreated subjects) and $25 \%$ in the antrum $(\mathrm{p}<0.001 v$ normal saline pretreated subjects).

Figure 2 shows that in normal saline pretreated subjects, ethanol lowered the cysteine concentration by $50 \%(\mathrm{p}<0.05)$ and by $63 \%$ $(\mathrm{p}<0.001)$ compared with basal values in the gastric body and antrum, respectively. Parenteral administration of glutathione not only prevented an ethanol induced drop in cysteine tissue values, but caused the cysteine concentration to increase by $69 \%(\mathrm{p}<0.05)$ and by $18 \%$ (p: NS) compared with baseline values in the gastric body and antrum, respectively.

A positive correlation was found between the gastric endoscopic score and the tissue concentration of glutathione in the gastric body $(r=$ $0.57, \mathrm{p}<0.01)$ and antrum $(\mathrm{r}=0.63, \mathrm{p}<0.01)$.

In order to evaluate the bioavailability of sulfhydryl compounds at the time of ethanol administration and of tissue sampling, we also evaluated the plasma concentration of glutathione and cysteine up to 70 minutes after the end of glutathione infusion $(2 \cdot 4 \mathrm{~g} / 100 \mathrm{ml} / 10$ minutes). The peak plasma concentration was reached at 25 minutes (that is, 15 minutes from the end of glutathione infusion) with a $>10$ fold increase in the glutathione concentration and a $>$ fourfold increase in the cysteine plasma concentration (Fig 3). At 35 minutes the glutathione concentration was back to the basal value, whereas it took almost 60 minutes for the cysteine to return to the baseline level (Fig 3).

\section{Discussion}

Ethanol induced damage to the gastric mucosa is associated with a significant decrease in glutathione gastric tissue values in experimental animals and humans. ${ }^{1-312}$ This reduction may have been contributed to by the following: (1) oxidation of glutathione because of ethanolinduced generation of toxic oxygen metabolites $^{13-15}$ or (2) binding of glutathione to acetaldehyde generated through the oxidation of ethanol by the gastric alcohol dehydrogenase activity, ${ }^{16} 17$ or both. The possibility that the decrease in glutathione brought about by ethanol is the result of leakage from damaged mucosa cannot be excluded.

Exogenous administration of sulfhydryl containing agents has been shown to prevent different forms of injury to the gastric mucosa in experimental animals in vivo ${ }^{1+518}$ as well as to gastric mucosal cells in vitro. ${ }^{19}$ Furthermore, experimental evidence indicates that endogenous glutathione plays an important role in maintaining the integrity of the gastric mucosa when this is challenged by damaging agents. In fact, depletion of gastric glutathione is associated with generation of gastric ulcers in the rat. ${ }^{20}$ In addition, depletion of endogenous sulfhydryls is associated with increased susceptibility of gastric mucous cells to oxygen metabolite- and acid 
induced cell damage in vitro..$^{21-23}$ The role of glutathione in gastric mucosal protection has, however, been questioned by other authors. ${ }^{2+25}$

Our hypothesis was that parenteral administration of glutathione might prevent the depletion of endogenous sulfhydryls induced by ethanol and thereby protect from ethanol injury. Eighty per cent ethanol significantly damaged the gastric body and antrum and decreased total sulfhydryl, glutathione, and cysteine concentrations. Infusion of glutathione did prevent the drop in total sulfhydryl compound gastric tissue concentrations and signficantly protected both the gastric body and antrum against ethanol injury. We postulate that ethanol induced depletion of gastric glutathione is counteracted by the increased bioavailability of glutathione and cysteine, which is known to be a precursor of glutathione synthesis. ${ }^{26}$ The maintenance of normal glutathione tissue concentrations might be responsible for the inhibition of ethanolinduced mucosal injury, possibly through scavenging of ethanol generated oxygen metabolites. ${ }^{27-30}$ The protective effect of parenteral glutathione may also be contributed to by the increase in gastric mucosal blood flow, ${ }^{31}$ stimulation of mucus production, ${ }^{32}$ or the inhibition of sulfhydryl containing proteases, ${ }^{33}{ }^{34}$ or all of the above. The hypothesis that glutathione-induced protection may be the result of the increased pool of the tripeptide is consistent with the glutathion and cysteine plasma concentrations reaching their peak values after glutathione infusion at the time of ethanol administration. Also, cysteine tissue values were found to be increased and glutathione gastric concentrations were almost back to normal in both the gastric body and antrum in glutathione-pretreated subjects despite ethanol administration. The increase in gastric cysteine might be accounted for by the degradation of the tripeptide by the $\alpha$-glutamyl transpeptidase at the outer cell surface and by an intracellular dipeptidase into glutamic acid, glycine, and cysteine, ${ }^{35}$ which are transported into the cells and re-used for glutathione synthesis. ${ }^{26}$ The inverse correlation between the gastric endoscopic score and the gastric glutathione concentration (that is, the higher the gastric concentration of glutathione the lower the gastric mucosal injury) is consistent with this hypothesis, even though it does not establish any cause and effect.

Our findings agree with a recent report by Hirota, et al who found that systemic administration of glutathione prevented stress induced gastric mucosal ulcer in rats. ${ }^{36}$ Furthermore, a recent study by Mutoh et al showed that preincubation with $\mathrm{N}$-acetyl-L-cysteine, a substrate for glutathione synthesis, prevented ethanolinduced damage to gastric mucosal cells in tissue culture and increased the cellular glutathione concentration..$^{37}$ In the same study, depletion of cellular glutathione increased ethanol-induced cytolysis. ${ }^{37}$ In addition, administration of DL-cysteine and DL-methionine sulfonium chloride, which is converted into cysteine, ${ }^{38}$ has been shown to stimulate the healing of nonsteroidal anti-inflammatory drug (NSAID) induced gastric mucosal lesions in humans. ${ }^{39}$

In conclusion, this is the first report showing that parenteral administration of glutathione prevents ethanol-induced depletion of gastric sulfhydryl compounds and decreases gastric mucosal injury brought about by ethanol in humans. Whether this is of clinical relevance needs further investigation with other substances that cause gastric injury such as aspirin or NSAIDs. Furthermore, dietary glutathione has been shown to be absorbed, resulting in an increase in plasma glutathione. ${ }^{+0}$ Since glutathione transport into epithelial cells allows its concentration to be maintained better than by synthesis alone, oral preparations whenever available, may enhance tissue availability of glutathione thereby providing the basis for prophylaxis against drug induced gastric mucosal damage.

Authors wish to thank C Castaldo and A Cerbone for technical assistance.

Data from this paper were presented in part at the Annual Data from this paper were presented in part at the Annua
Meeting of the American Gastroenterological Association, New Meeting of the American Gastroenterological Association, New (Gastroenterology; 100: A113, 1991).

1 Szabo S, Trier JS, Frankel PW. Sulfhydryl compounds may mediate gastric cytoprotection. Science 1981; 214: 200-2.

2 Miller TA, Li D, Kuo YJ, Schmidt KL, Shanbour LL. Nonprotein sulfhydryl compounds in canine gastric mucosa: Nonprotein sulfhydryl compounds in canine gastric mucosa:
effects of PGE2 and ethanol. Am $₹$ Physiol 1985; 249: effects of

3 Loguercio C, Romano M, Di Sapio M, Nardi G, Taranto D, Grella $\mathrm{A}$, et al. Regional variations in total and nonprotein sulfhydryl compounds in the human gastric mucosa and effects of ethanol. Scand $\mathcal{F}$ Gastroenterol 1991; 26: 1042-8.

4 Ghanayem BI, Boor PJ, Ahmed AE. Acrylonitrile-induced gastric mucosal necrosis: role of gastric glutathione. f Pharmacol Exp Ther 1985; 232: 570-7.

5 Rogers C, Brown A, Szabo S. Gastric mucosal protection by new aryl sulfhydryl drugs. Dig Dis Sci 1988; 33: 324-9.

6 Agrawal NM, Godiwala T, Arimura A, Dajani E. Comparative cytoprotective effects against alcohol insult. Misoprostol versus cimetidine. Dig Dis Sci 1986; 31 (suppl): 142S.

7 Ellman GL. Tissue sulfhydryl groups. Arch Biochem Biophys 1959; 82: 70-7.

8 Newton GL, Dorian R, Fahey RC. Analysis of biological thiols: derivatization with monobromobimane and separation by reverse phase high pressure liquid chromatography. Anal Biochem 1981; 114: 383-7.

9 Nardi G and Cipollaro M. 1-Methyl-4-thiohistidine and glutathione in the developing embryo of the Sea Urchin, Paracentrotus Lividus. Develop Growth and Differ 1988; 30 : 383-8.

10 Loguercio C, Nardi G, Prota G, Del Vecchio Blanco C, Coltorti $M$. Decrease of total, glutathione and cysteine SH in non-alcoholic cirrhosis. Ital f Gastroenterol 1990; 22: 13-5.

11 Duncan DB. Multiple range and multiple F tests. Biometrics 1955; 11: 1-42.

12 Victor BE, Schmidt KL, Smith GS, Miller TA. Protection against ethanol injury in the canine stomach: role of mucosal against ethanol injury in the canine stomach: rol
glutathione. Am $\mathcal{f}$ Physiol 1991; 261: G966-73.

13 Pihan G, Regillo C, Szabo S. Free radicals and lipid peroxidation in ethanol- and aspirin-induced gastric mucosal injury. Dig Dis Sci 1987; 32: 1395-401.

14 Szelenyi $I$ and Brune $K$. Possible role of oxygen free radicals in ethanol-induced gastric mucosal damage in rats. Dig Dis $\mathrm{Sc}$ 1988; 33: 865-71

15 Shaw S, Herbert V, Colman N, Jayatilleke E. Effect of ethanol-generated free radicals on gastric intrinsic factor and glutathione. Alcohol 1990; 7: 153-7.

16 Hernandez-Munoz R, Caballeria J, Baraona E, Uppal R, Greenstein R, Lieber CS. Human gastric alcohol dehydrogenase: its inhibition by $\mathrm{H} 2$-receptor antagonists, and its effect on the bioavailability of ethanol. Alcohol Clin Exp Res effect on the bioa

17 Baraona E, Di Padova C, Tabasco J, Lieber CS. Transport of acetaldehyde in red blood cells. Alcohol Alcoholism 1987 (suppl 1): 203-6.

18 Gutierrez-Cabano CA. Probable role of both sulfhydryls and prostaglandins in gastric mucosal protection induced by $\mathrm{S}$ Adenosylmethionine. Scand F Gastroenterol 1989; 24: 982-6.

19 Romano M, Razandi M, Raza A, Szabo S, Ivey KJ Cysteamine protects gastric epithelial cell monolayers against drug-induced damage: evidence for direct cellular protection by sulfhydryl compounds. Gut 1992; 33: 30-8

20 Boyd SC, Sasame HA, Boyd MR. Gastric glutathione depletion and acute ulcerogenesis by diethylmaleate given subcutaneously to rats. Life Sci 1981; 28: 2987-92.

21 Romano M, Razandi M, Ivey KJ. Role of sulfhydryl compounds in the defense of rat gastric epithelial cells against oxygen reactive metabolite-induced damage. Ital 7 Gastroenterol 1991; 23: 55-9. 
22 Hiraishi H, Terano A, Ota S, Mutoh H, Sugimoto T, Razandi $M$, et al. Antioxidant defenses of cultured gastric cells against oxygen metabolites: role of GSH redox cycle and endogenous catalase. Am $\mathcal{F}$ Physiol 1991; 261: G921-8.

23 Mutoh H, Ota S, Hiraishi H, Ivey KJ, Terano A, Sugimoto T. Reduced glutathione protects cultured gastric mucosal cells from suckling rats against acid. Am $\mathcal{F}$ Physiol 1991; 261 : G65-70.

24 Robert A, Eberle D, Kaplowitz N. Role of glutathione in gastric mucosal cytoprotection. Am $\mathcal{F}$ Physiol 1984; 247: gastric muco

25 Takeuchi K, Okada M, Niida H, Okabe S. Role of sulfhydryls in mucosal injury caused by ethanol: relation to microvascular permeability, gastric motility and cytoprotection. F Pharmacol Exp Ther 1989; 248: 836-41.

26 Deneke SM and Fanburg BL. Regulation for cellular glutathione. Am F Physiol 1989; 257: L163-73.

27 Flohe L. Glutathione peroxidase: fact and fiction. In: Oxygen free radicals and tissue damage. CIBA Foundation Symposium 65. Amsterdam: Excerpta Medica, 1979: 95-122.

28 Kaplowitz N, Aw TY, Ookhtens M. The regulation of hepatic glutathione. Ann Rev Pharmacol Toxicol 1985; 25: 714-4.

29 Olson CE. Glutathione modulates toxic oxygen metabolite injury of canine chief cell monolayers in primary culture. injury of canine chief cell mono

30 McCoy RN, Hill KE, Ayon MA, Stein JH, Burk RF. Oxidant stress following renal ischemia: changes in the glutathione redox ratio. Kidney 1988; 33:812-7.

31 Szabo S, Trier JS, Brown A, Schnoor J. Early vascular injury and increased vascular permeability in gastric mucosa injury caused by ethanol in the rat. Gastroenterology 1985; 88: 228-36.
32 Lamont JT, Ventola S, Maull EA, Szabo S. Cysteamine and prostaglandin $F 2$ beta stimulate rat gastric mucin release. Gastroenterology 1983; 84: 306-13.

33 Dupuy D, Szabo S. Protection by metals against ethanolinduced gastric mucosal injury in the rat - Comparative biochemical and pharmacologic studies implicate protein sulfhydryls. Gastroenterology 1986; 91: 966-74.

34 Szabo S, Nagy L, Johnson BR. Protein and nonprotein sulfhydryls as targets of gastroprotective and antiulcer drugs. Dig Dis Sci 1990; 35: 1041A

35 Tate SS. Glutathione-degrading enzymes of brush-border in molecular and functional aspects. In: Taniguchi N, Higashi molecular and functional aspects. In: Taniguchi N, Higashi T, Sakamoto Y, Meister A, eds. Glutathione centennialMolecular prospective and clinical
Academic Press, 1989: 189-208.

36 Hirota $M$, Inoue $M$, Ando Y, Hirayama $K$, Morino $Y$, Sakamoto K, Mori H, Akagi M. Inhibition of stress-induced gastric injury in the rat by glutathione. Gastroenterology 1989; 97: 853-9.

37 Mutoh H, Hiraishi H, Ota S, Yoshida H, Ivey KJ, Terano A, et al. Protective role of intracellular glutathione against ethanol-induced damage in cultured rat gastric mucosal cells. Gastroenterology 1990; 96: 1452-9.

38 Turner FP, Brum VC, Bilodeau EG. Incorporation of 35SLmethionine by the rat with steroid ulceration. 7 Maine Med Assoc 1977; 68: 227-43.

39 Salim AS. Sulfhydryls protect patients against complications of erosive gastritis. Dig Dis Sci 1990; 35: 1436-8.

40 Hagen TM, Wierzbicka GT, Sillau AH, Bowman BB, Jones DP. Bioavailability of dietary glutathione: effect on plasma
DPen concentration. Am F Physiol 1990; 259: G524. 